\title{
Comparison of Heat Flux Gages for High Enthalpy Flows - NASA Ames and IRS
}

\author{
Stefan Loehle*, \\ Universität Stuttgart, Institut für Raumfahrtsysteme, 70569 Stuttgart, Germany \\ Anuscheh Nawaz \\ Jacobs Technology, Inc, Moffett Field, CA 94035, USA \\ Georg Herdrich,, Stefanos Fasoulas \\ Universität Stuttgart, Institut für Raumfahrtsysteme, 70569 Stuttgart, Germany \\ Edward Martinez, [George Raichell \\ NASA Ames Research Center, Moffett Field, CA 94035, USA
}

\begin{abstract}
This article is a companion to a paper on heat flux measurements as initiated under a Space Act Agreement in 2011. The current focus of this collaboration between the Institute of Space Systems (IRS) of the University of Stuttgart and NASA Ames Research Center is the comparison and refinement of diagnostic measurements. A first experimental campaign to test different heat flux gages in the NASA Interaction Heating Facility (IHF) and the Plasmawindkanäle (PWK) at IRS was established. This paper focuses on the results of the measurements conducted at IRS. The tested gages included a flat face and hemispherical probe head, a 4" hemispherical slug calorimeter, a nullpoint calorimeter from Ames and a nullpoint calorimeter developed for this purpose at IRS. The Ames nullpoint calorimeter was unfortunately defective upon arrival. The measured heat fluxes agree fairly well with each other. The reason for discrepancies can be attributed to signal-to-noise levels and the probe geometry.
\end{abstract}

\section{Introduction}

In October 2011, a Space Act Agreement (SAA) between NASA Ames Research Center and the Institute of Space Systems (IRS) was put in place to make use of the high level of expertise on both sides in the operation of high enthalpy facilities and advanced diagnostic methods. The SAA calls for joint testing, in which arc jet plasma diagnostic instrumentation of IRS is applied to the high-power plasma arc jets at the NASA Ames Research Center (ARC) and vice versa. In a first step, tests were conducted with null-point sensors and calorimeters from both institutions tested at ARC and IRS facilities. ${ }^{1}$ This approach is used to compare sensors and facilities, laying the groundwork for future activities and joint tests. This paper presents the second part - the testing at IRS with ARC and IRS sensors.

Among the available diagnostic techniques for high enthalpy flows in the two institutions, heat flux as an essential performance parameter and its measurement is highly valuable for the understanding of re-entry plasma flows. The arc jet tests described in this paper are intended to compare heat flux measurements and analysis techniques. In particular (reproduced from ${ }^{1}$ ):

${ }^{*}$ Research Scientist, Group Leader, High Enthalpy Flow Diagnostics, IRS, Member AIAA

¥Professor, Group Leader, Plasma Wind Tunnels and Electric Propulsion, Senior Member AIAA

$\S$ Professor, Director, Senior Member AIAA

ISenior Research Engineer, NASA Ames Research Center, Moffett Field, CA 94035, USA, ed.martinez@nasa.gov

$\|$ Branch Chief Thermophysics Facilities 
1. ARC slug calorimeter measurements shall be compared to the IRS water-cooled calorimeter, and

2. ARC Null-point data analysis shall be compared to IRS data analysis and calibration technique.

The null-point calorimeters were all calibrated using the in-house calibration procedure. The Non-Integer System Identification (NISI) method allows to calibrate the thermal response of a sensor system of interest for transient heat flux measurements. The sensor system is therefore installed in a calibration setup where a known heat load provided by a laser allows to characterize the thermal response. This calibration is a non-destructive procedure so that the sensor can be used afterward in the wind tunnel. The maximum laser power is $500 \mathrm{~W}$ resulting in about $1 \mathrm{MW} / \mathrm{m}^{2}$ for the sensors applied in this study. The NISI method was first applied to the classical nullpoint sensor. ${ }^{2}$ Meanwhile many different sensor systems were calibrated and tested. There are also similar approaches based on this idea, but still based on the analytical approach of the inverse heat conduction problem. ${ }^{3}$ The calibration is completed prior to testing in the plasma wind tunnel and does not affect the nullpoint data acquisition (temperature vs. time) during testing. Post-test calibration allows furthermore the investigation of possible sensor changes, e.g. surface state, during testing. The main advantage of the calibration procedure is that the heat flux is measured without the requirement of knowing thermo-physical properties, the exact positioning of the thermocouple (or the required assumption in heat conduction defining the so-called null-point) and thermocouple inertia issues. ${ }^{4}$ Thus, a comparison of the heat flux data at the same conditions in the different facilities allows a deeper insight into the heat flux data analysis procedures.

In the following the facility and the sensors involved at IRS are described in more detail. The third section presents the measured heat flux data from the different sensors as measured at IRS. Following this, these data sets are compared with the measurement campaign at ARC in section IV. And finally, steps are identified in order to make heat flux measurements even more reliable.

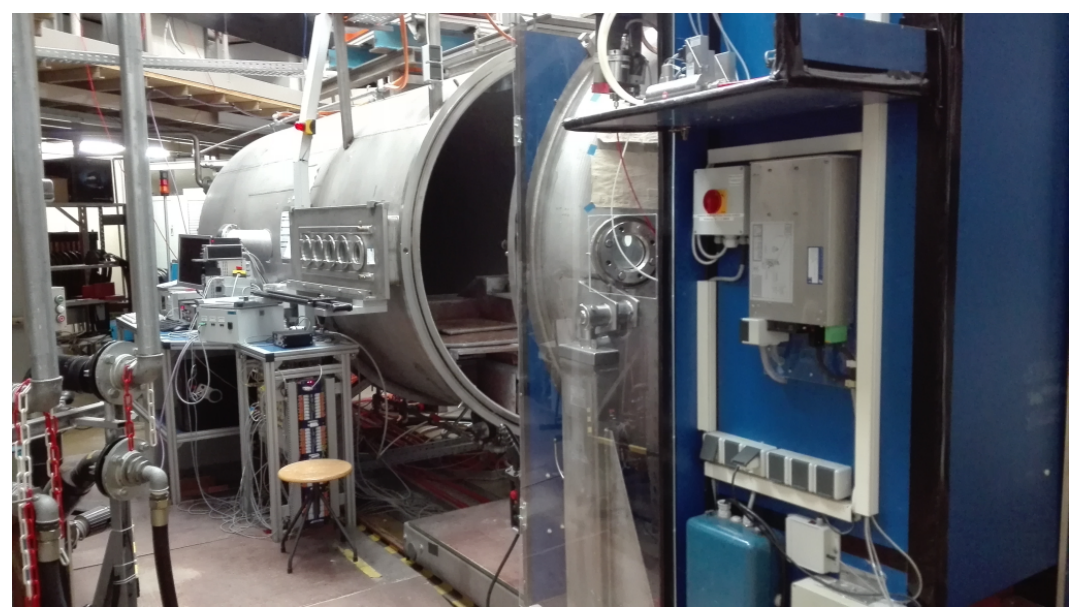

Fig. 1: Plasma wind tunnel PWK4 at IRS.

\section{Facility and Sensors Involved}

This section provides a description of the plasma wind tunnel facility at IRS and the different sensors used. Figure 1 shows a photography of the facility PWK4. ${ }^{5}$ 


\section{A. Plasma Wind Tunnel PWK4}

For the present investigation the plasma wind tunnel PWK4 was used. ${ }^{6}$ It provides high enthalpy, supersonic air plasma flows relevant for the investigation of Earth entries from low earth orbits at altitudes between $50 \mathrm{~km}$ and $30 \mathrm{~km}$.

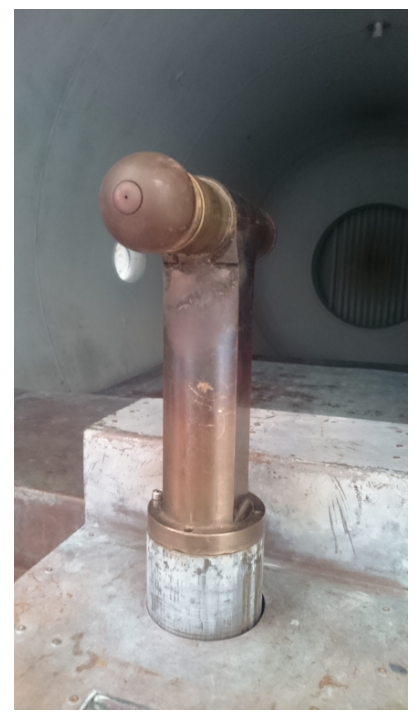

Fig. 2: $50 \mathrm{~mm}$ hemispherical probe head. Total pressure port on the backside.
The plasma wind tunnel PWK4 is equipped with a thermal arc-jet generator RB3, which is attached to the movable front lid of the vacuum chamber (diameter: $2 \mathrm{~m}$, length: $6 \mathrm{~m}$ ). Vacuum is realized with a centralized common vacuum pumping system. ${ }^{5}$ A major refurbishment of this system in 2014 resulted in lower end pressure in the chamber, but the major advantage of the new system is the improved ambient pressure adjustment. ${ }^{5}$ The vacuum chamber walls are water-cooled and a high pressure water cooling circuit provides high cooling rates for the copper cooling shields and the probe holder inside the vacuum chamber. A movable platform allows fast and programmable positioning of the probes. Depending on the back pressure in the chamber, the position in the flow with respect to the nozzle exit plane, the gas mass flow and input power on the generator, a flow condition is defined.

The power supply system at IRS is a $6 \mathrm{MW}$ DC power converter based on 6 current-regulated thyristor rectifiers. ${ }^{5}$

The reachable total pressures at the IRS facilities are significantly lower than at ARC. Therefore, one condition was defined which both facilities can provide. A well characterized second condition was chosen where additional flow parameters are known from previous measurements. ${ }^{7,8}$ This would eventually allow to get more insight into the flow field parameters. Table 1 shows the parameters of the two conditions.

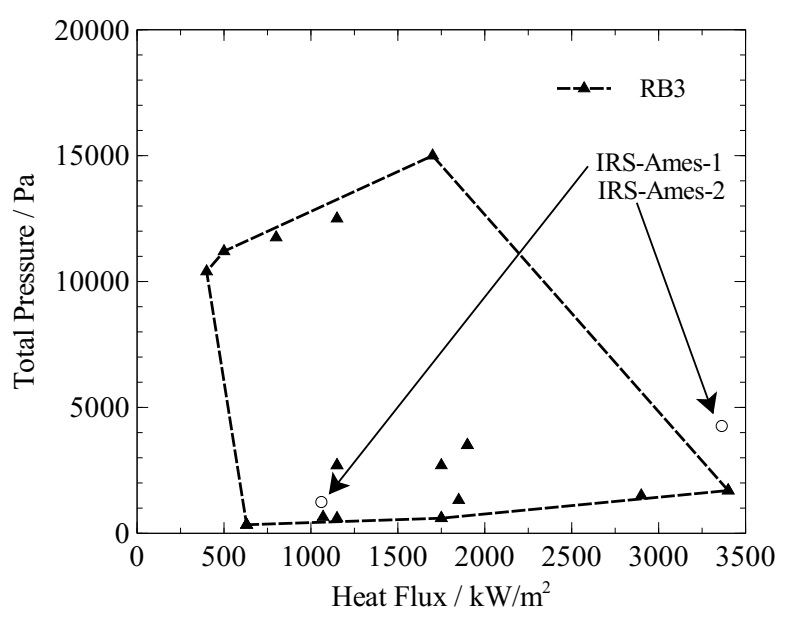

Fig. 3: Available experimental conditions for air plasma at IRS, and test conditions chosen (scaled to $50 \mathrm{~mm}$ flat faced probe head).

Figure 3 shows a graph with flow conditions that are regularly used. The two conditions of the present investigations are added with open symbols. The required condition with higher heat flux and total pressure is outside the commonly known flow conditions. It is this condition that was intended to be comparable to the condition Ames-IRS1 of the campaign at ARC. ${ }^{1}$ The condition was newly established. The reference data set for the condition are total pressure and heat flux. Both can be measured with one probe which has two probe heads: ${ }^{9}$ On one side heat flux is measured on a $50 \mathrm{~mm}$ hemispherical water-cooled calorimeter, on the opposite side a total pressure port. During wind tunnel testing the probe can be moved outside of the plasma flow and turned by $180^{\circ}$ so that either the heat flux probe head or the total pressure probe head are facing the flow. Then, the probe is moved back into position on the plasma axis. Both heat flux and total 
Table 1: PWK4 flow conditions.

\begin{tabular}{lll}
\hline Parameter & IRS-Ames-1 (low) & IRS-Ames-2 (high) \\
\hline \hline Ambient pressure $p_{a m b}$ & $65 \mathrm{~Pa}$ & $640 \mathrm{~Pa}$ \\
Current $I$ & $600 \mathrm{~A}$ & $883 \mathrm{~A}$ \\
Voltage $U$ & $93 \mathrm{~V}$ & $87.5 \mathrm{~V}$ \\
Electric input power $P_{e l}$ & $55.8 \mathrm{~kW}$ & $77.3 \mathrm{~kW}$ \\
Nitrogen gas mass flow $\dot{m}_{\mathrm{N}_{2}}$ & $5 \mathrm{~g} / \mathrm{s}$ & $3.83 \mathrm{~g} / \mathrm{s}$ \\
Oxygen gas mass flow $\dot{m}_{\mathrm{O}_{2}}$ & $1.52 \mathrm{~g} / \mathrm{s}$ & $1.16 \mathrm{~g} / \mathrm{s}$ \\
Axial Position $x$ & $90 \mathrm{~mm}$ & $81 \mathrm{~mm}$ \\
Total pressure $p_{\text {tot }}$ & $1243 \mathrm{~Pa}$ & $4262 \mathrm{~Pa}$ \\
\hline
\end{tabular}

pressure needed to be measured about 5 times to adjust the required condition for comparison with ARC. The parameters to be adjusted are back pressure, axial position and generator input power, i.e. current. The adjustment starts with a measurement of the total pressure. Thus, the total pressure probe head faces the plasma. Then current and ambient pressure are adjusted. When the required total pressure value is found, the probe is moved outside the flow, is turned so that the heat flux probe head faces the flow and is moved back in position. Again, current, pressure and/or position are adjusted to meet the heat flux value. Then, total pressure is checked again, which means the probe is turned to have the total pressure probe head facing the flow. This procedure is repeated until both heat flux and total pressure requirements are met. Finally, the measured heat flux on the $50 \mathrm{~mm}$ hemispherical probe head is then scaled to the larger hemisphere of the NASA probe $(102 \mathrm{~mm})$ by the well known scaling of heat flux with $\sqrt{r}$ for supersonic flows. ${ }^{10}$

Table 2 shows the comparison of the two tested conditions in IHF and in PWK4. The naming convention is taken from the previous paper ${ }^{1}$ and is the following: The place where the heat flux was measured is named in first place, the numbering denotes a low (1) and a high (2) condition. The high condition at IRS was adjusted to be the same as the low condition at Ames (IRS-Ames- $2 \approx$ Ames-IRS-1) The data is scaled to the $102 \mathrm{~mm}(4$ ") hemispherical value. The first condition with lower heat flux and total pressure is often used in this facility for the investigation of aerothermochemistry and spectroscopy for low Earth orbit entry simulation..$^{7,8,11}$ As desired IRS-Ames-2 and Ames-IRS1 (the two middle columns) are close to each other.

Table 2: Overview of flow conditions in PWK4 and IHF.

\begin{tabular}{lllll}
\hline Parameter & IRS-Ames-1 & IRS-Ames-2 & Ames-IRS1 & Ames-IRS2 \\
\hline \hline total pressure $p_{\text {tot }}$ & $1243 \mathrm{~Pa}$ & $4262 \mathrm{~Pa}$ & $4250 \mathrm{~Pa}$ & $23100 \mathrm{~Pa}$ \\
heat flux $I$ & $74 \mathrm{~W} / \mathrm{cm}^{2}$ & $237 \mathrm{~W} / \mathrm{cm}^{2}$ & $239 \mathrm{~W} / \mathrm{cm}^{2}$ & $638 \mathrm{~W} / \mathrm{cm}^{2}$ \\
\hline
\end{tabular}

Both conditions were tested in one single plasma wind tunnel run. Since IRS-Ames-1 is a well known standard flow condition, it was adjusted first to exclude possible facility issues. Then, the second (unknown) condition was tested.

The movable platform was programmed in order to position the probes as specified. The four axis positioning computer is newly installed and enables fast crossing of the plasma jet required for the nullpoint testing. The actual position and the temperature data were acquired with a separate external oscilloscope (LeCroy Wavesurfer 24x), because the sampling rate of the standard data acquisition (about $3 \mathrm{~Hz}$ ) is too low to measure transient heat flux gage data. The oscilloscope acquired with a sampling frequency of $500 \mathrm{kHz}$. All other facility parameters were acquired as usual, i.e. about 45 monitoring values of pressure readouts, temperatures and flow rates are acquired throughout the whole experiment. During testing, all parameters can be visualized in separate graphs which is particularly useful to verify that the conditions are steady state.

Except for the water cooled calorimeters being a completely integrated probe itself, all heat flux sensors were mounted on the same probe head. All thermocouple data was fed with appropriate compensating wires to the thermocouple amplifier (AD595) with integrated cold junction. It is worth noting that data amplification 
at Ames is different. At Ames, the data is first filtered by $2 \mathrm{kHz}$ low pass filter before amplifying by 100 followed by the $\mathrm{AD}$ conversion with 16 bit to a signal range of $\pm 10 \mathrm{~V}$.

\section{B. Slug Calorimeters}

Slug calorimeters are used in standard arc-jet characterization runs at ARC. They consist of a cylindrical slug made of oxygen free high conductivity copper (see Fig.B). This slug is insulated against the rest of the calorimeter body and held in position through ruby balls. A thermocouple at the backside of the slug measures the temperature rise as the calorimeter is exposed to heat flux. ${ }^{12}$

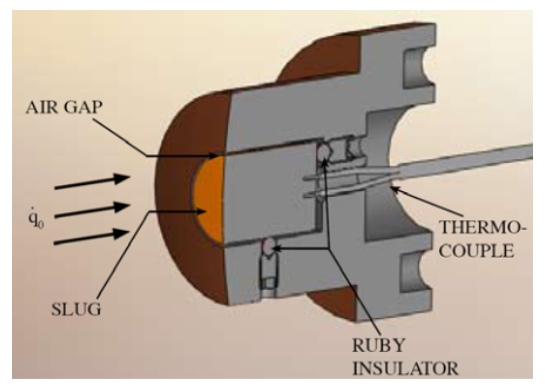

Fig. 4: Principle setup of a slug calorimeter (reproduced from ${ }^{12}$ ). shows the flat faced $50 \mathrm{~mm}$ slug calorimeter in the same situation.

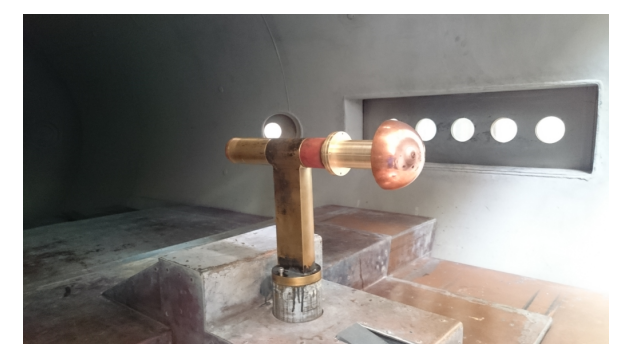

The dimensions of the slugs are measured accurately and the slug is weighed so that the heat capacity is known with sufficient accuracy. For this test series, the standard $102 \mathrm{~mm}$ diameter hemispherical slug calorimeter serves as a link to historical data acquired by the ARC facilities. ${ }^{13}$ In addition, a $50 \mathrm{~mm}$ diameter flat face slug calorimeter was manufactured for this cooperation. It copies the outside geometry of the IRS flat faced water cooled calorimeter and was built to compare the heat flux values measured with both techniques. The $102 \mathrm{~mm}(4$ ") hemispherical slug calorimeter was mounted with an adapter ring to the probe holder at IRS. Figure 5 shows the $102 \mathrm{~mm}(4 ")$ hemispherical slug calorimeter mounted in the wind tunnel and during testing at the high condition. Figure 6

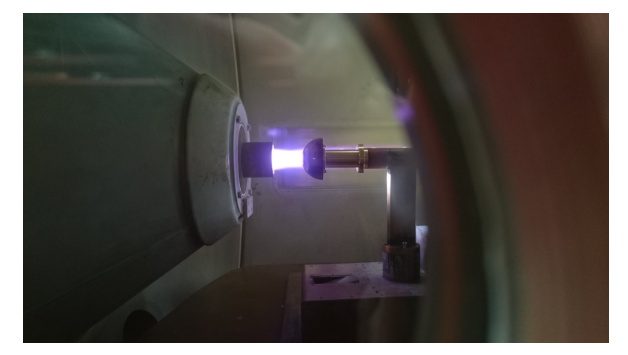

Fig. 5: Photo before (left) and during (right, IRS-Ames-2) test of the $102 \mathrm{~mm}$ (4") hemispherical slug calorimeter.
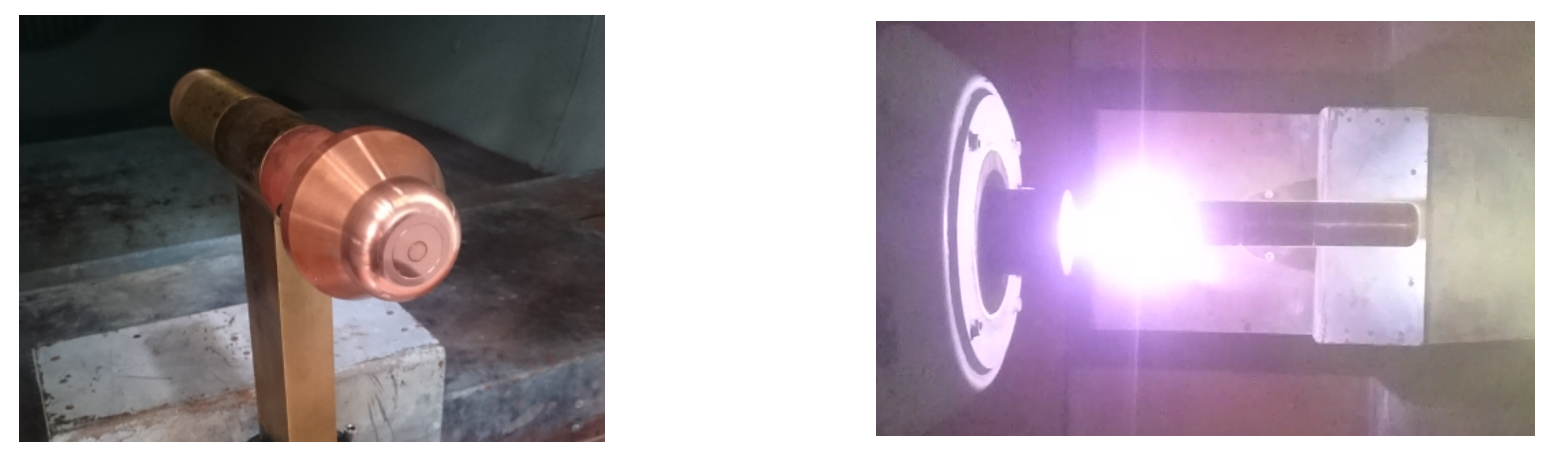

Fig. 6: Photo before (left) and during (right, IRS-Ames-2) test of the $50 \mathrm{~mm}$ flat faced slug calorimeter.

The heat flux onto the slug calorimeter is determined through the temperature increase registered at the back of the thermally insulated slug. ${ }^{14}$ Therefore, the probe is moved quickly in position on the center axis of the jet and kept in the center for 1-2 s before it is removed out of the plasma. The temperature increase during the time the probe is in position is linear and the slope of this temperature increase is a measure for the heat flux. Furthermore, the transient data can be analyzed to measure a heat flux profile of the jet. 


\section{IRS Water-cooled calorimeter}

The water cooled calorimeter of IRS is an in house development that started in the early 1990s and continuously improved to the current design (see Figs. 7,8). The probe head was damaged likely due to heating during the campaign at ARC. ${ }^{1}$ The whole inner structure was therefore replaced and new resistance thermometers (pt100) were installed for this campaign. The working principle of this calorimetric is the following:

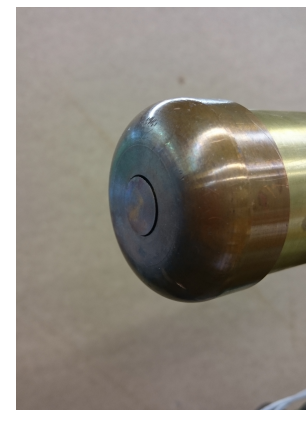

Fig. 7: Photography of the IRS water cooled calorimeter probe head.

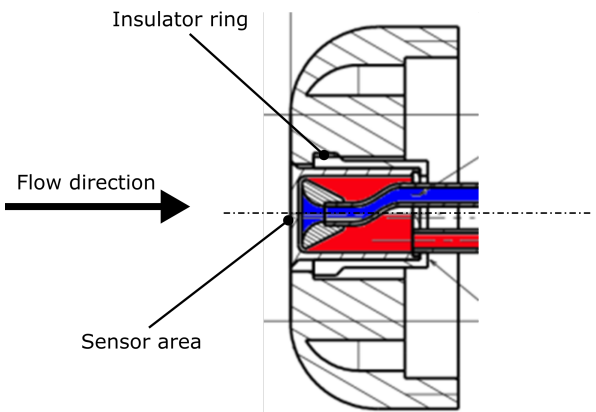

Fig. 8: Cross section of the water cooled calorimeter probe head.

A well insulated surface of the probe in the stagnation region is cooled by a separate water cooling circuit. The inlet and outlet temperature $\left(T_{\text {inlet }}, T_{\text {outlet }}\right)$ as well as the cooling water mass flow $\dot{m}_{\mathrm{H}_{2} \mathrm{O}}$ are measured and the heat flux $\dot{q}$ results then in

$$
\dot{q}=\frac{\dot{m}_{H_{2} O} c_{p}\left(T_{\text {outlet }}-T_{\text {inlet }}\right)}{A},
$$

where $c_{p}$ stands for the heat capacity of the water. This value is assumed to be constant in the temperature range of interest. ${ }^{15}$ The same sensor principle was also used with a $50 \mathrm{~mm}$ hemispherical probe head (see Fig. 2). This probe is usually used for local mass-specific enthalpy measurements which is also based on the measurement of stagnation point heat flux. ${ }^{9,16,17}$ For the present investigation, this probe was used for the establishment of the IRS-Ames-2 flow condition, because it was readily available while the $50 \mathrm{~mm}$ flat faced water-cooled calorimeter had to be repaired.

A critical issue widely investigated by many researchers for these sensors with copper surfaces is the surface's oxidation state. The surface catalytic behavior depends heavily on the oxidation state. Nawaz et al. investigated different oxidation states in Aerodynamic Heat Facility (AHF), but also concluded that a polished surface is hardly existent, because the atmospheric air already results in a thin copper oxide layer. ${ }^{18}$ Measurements in the facility with slug calorimeters further show that a further oxidation needs to be considered in the data evaluation.

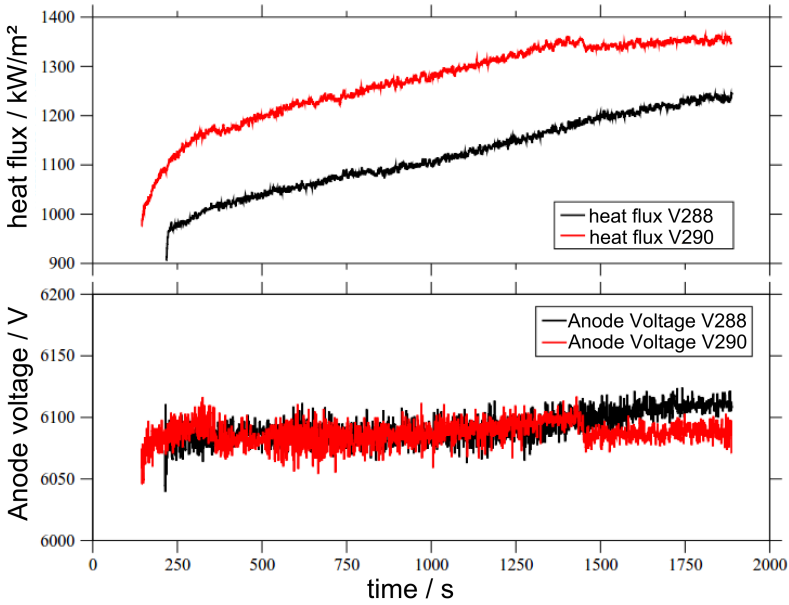

Fig. 9: Heat flux increase at constant facility parameters. ${ }^{9,15}$
At IRS the catalytic behavior of many materials have been under investigation since the mid 1990s. ${ }^{19,20}$ Since the water cooled calorimeter can be positioned for extended periods of time in the plasma flow, the heat flux behavior can be analyzed with steady state plasma conditions. An oxidation of the surface was observed asymptotically going to a constant value after $20 \mathrm{~min}$. The plot from Laux et al. is reproduced in Fig. 9 to show this observation.

As a consequence, the IRS water cooled calorimeter is preoxidized by heating the sensor surface to about $700 \mathrm{~K}$ for $20 \mathrm{~min}$ under atmospheric 
conditions in a furnace. A dark black layer forms on the surface which is not well connected to the surface. The copper oxide which is seen below this layer is assumed to be the oxidation state with the highest catalytic efficiency to atomic oxygen and nitrogen. A systematic verification of this approach has not been conducted so far nor were there surface analysis performed to confirm the surface oxidation state.

\section{Null point calorimeter}

The nullpoint calorimeter is a transient heat flux gage. The sensor passes through the plasma jet and the heating is recorded by measuring the in-depth temperature. Two different nullpoint calorimeters were tested: The standard Ames nullpoint calorimeter according to ASTM E-598-96 and a recently established miniaturized nullpoint calorimeter at IRS. ${ }^{4}$

The application of the NISI method requires a calibration using a high power laser system. At IRS, the calibration setup was used which consists in a $500 \mathrm{~W}$ diode laser system at $980 \mathrm{~nm} .{ }^{21}$ The reflectivity of oxidized and polished copper were measured by the French Energy Commission (CEA) (see Fig. 10 ${ }^{22}$ ) and is considered to be $r=0.85$ for the oxidized nullpoints and $r=0.52$ for polished copper. The absorptivity is then $\alpha=1-r$.
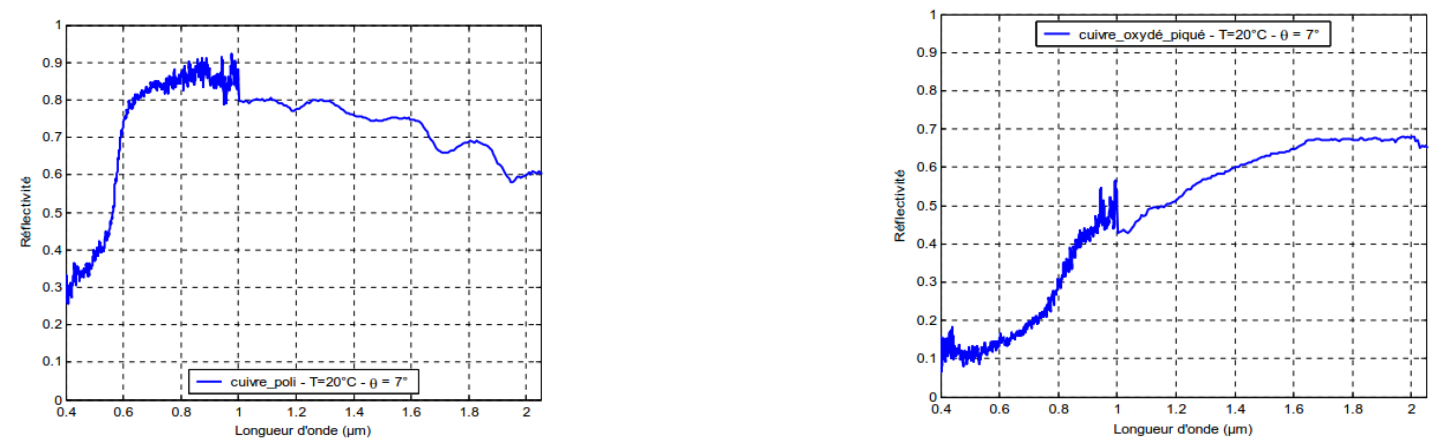

Fig. 10: Measured reflectivities for Copper, polished (left) and oxidized (right) (courtesy CEA).

The oxidation state of copper surfaces for heat flux gages is still one of the major issues for the accuracy of heat flux measurements. ${ }^{18}$ For the present investigation, it was attempted to keep the measurement procedure at Ames and IRS the same for comparison reasons. Therefore, the slug calorimeters were left polished, although at IRS usually, the sensors are preoxidized in a furnace (see above description).

\section{Ames Nullpoint Calorimeter}

The Ames Nullpoint calorimeter dates back to a sensor development in the 1970s. The sensors were originally developed for extreme heat flux measurements in the AEDC arc-jet facilities. ${ }^{23}$

This sensor type is also applied in the plasma wind tunnels at Airbus in Bordeaux, France and was improved by using the NISI calibration method. ${ }^{2}$ With this calibration approach, miniaturized sensors were developed which thus achieve better geometrical resolution. ${ }^{24}$

The nullpoint calorimeter provided by ARC arrived with a broken thermocouple wire. The system was repaired at IRS and re-calibrated with the NISI method. However, it was not possible to perform successful testing due to a defective contact which could not be located.

\section{IRS Nullpoint Calorimeter}

This nullpoint calorimeter has been designed especially for this cooperative measurements. Using the approximate values from the slug calorimeter and the water cooled calorimeter, a trade off in probe size for reasonable signal-to-noise and small sensor size has been found. The sensor tip has an outer diameter of $20 \mathrm{~mm}$ and a cylindrical form. The design of the IRS nullpoint is relatively simple. It consists of a copper block with appropriate outer geometry and a single small bore which is drilled as close to the tip as possible. Then, a $0.15 \mathrm{~mm}$ sheathed thermocouple is fed into the bore aiming at having a good contact to the copper. 

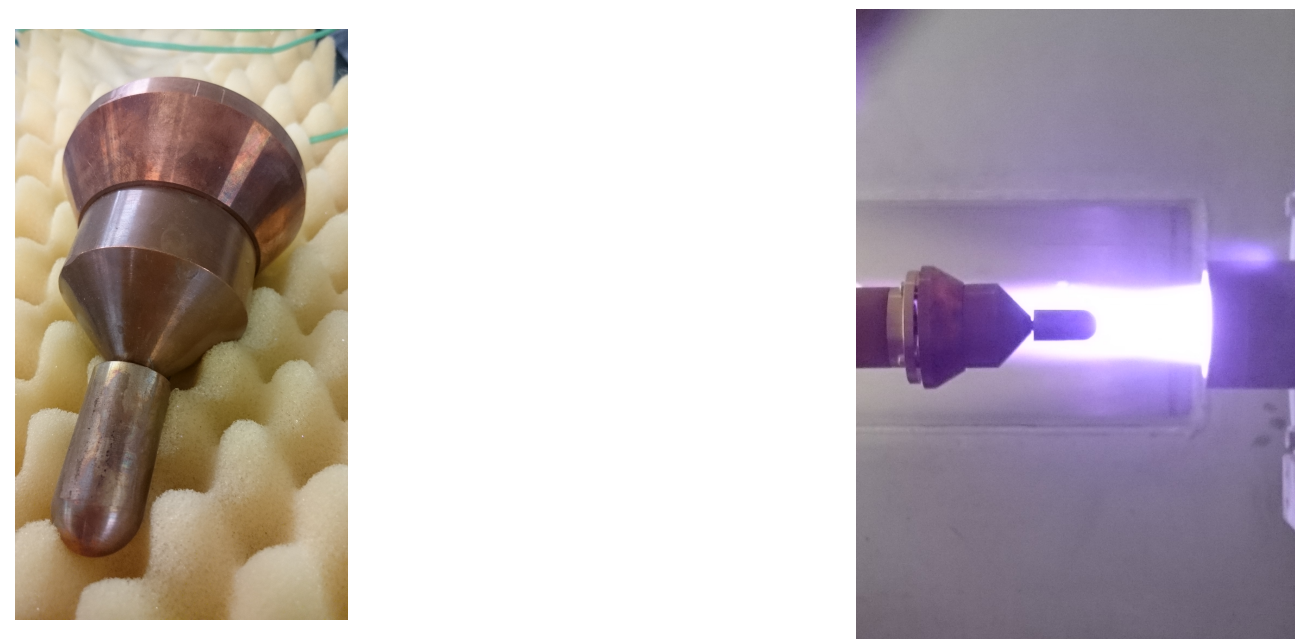

Fig. 11: IRS nullpoint calorimeter with $20 \mathrm{~mm}$ hemisphere: photography (left) and during experiment (right).

This nullpoint can only be used by applying the NISI method. The classical nullpoint theory fails, because the design does not guarantee the required one-dimensional heat conduction throughout the testing as required to apply the inverse method of ASTM E-598-96. ${ }^{4}$

\section{Results}

Table 3 summarizes all measured results. The values here are the heat flux values after applying the corresponding data analysis, i.e. without any further scaling. The first line are the values required for testing in order to be in line with the Ames flow condition. The NASA nullpoint data are not available due to

Table 3: Measured heat flux values on the different sensor geometries.

\begin{tabular}{lll}
\hline Probe & IRS-Ames-1 in W/cm ${ }^{2}$ & IRS-Ames-2 in W/ $\mathrm{cm}^{2}$ \\
\hline \hline Water-cooled calorimeter $50 \mathrm{~mm}$, hemispherical & 101.3 & 373.3 \\
Water-cooled calorimeter $50 \mathrm{~mm}$, flat faced probe head & - & - \\
Slug calorimeter $102 \mathrm{~mm}$ hemispherical & 79 & 184 \\
Slug calorimeter $50 \mathrm{~mm}$ flat faced & 70 & 170 \\
NASA Nullpoint & - & - \\
IRS Nullpoint $20 \mathrm{~mm}$ hemispherical & 69.8 & 522.4 \\
\hline
\end{tabular}

the broken sensor, the water-cooled calorimeter data is missing due to the same malfunctioning observed at Ames. ${ }^{1}$

The measured heat flux values can be compared by scaling the data to the 4" (102 mm) hemispherical probe head using well known analytical relations. According to the relation of Zoby and Sullivan, the effective nose radius of the $50 \mathrm{~mm}$ flat faced probe is $r_{\mathrm{eff}}=2.3 \cdot r_{50 \mathrm{~mm}}=115 \mathrm{~mm} .^{25,26}$

The different hemispherical probes scale with the square root of the radius, i.e. for the $50 \mathrm{~mm}$ flat faced geometry with effective diameter of $62.5 \mathrm{~mm}$

$$
q_{102 \mathrm{~mm}}=q_{50 \mathrm{~mm}} \sqrt{\frac{115}{102}}=q_{50 \mathrm{~mm}} \cdot 1.06,
$$

for the $20 \mathrm{~mm}$ hemispherical IRS nullpoint

$$
q_{102 \mathrm{~mm}}=q_{20 \mathrm{~mm}} \sqrt{\frac{20}{102}}=q_{20 \mathrm{~mm}} \cdot 0.44
$$


and for the $9.2 \mathrm{~mm}$ sphere cone nullpoint

$$
q_{102 \mathrm{~mm}}=q_{9.2 \mathrm{~mm}} \sqrt{\frac{9.2}{102}}=q_{20 \mathrm{~mm}} \cdot 0.3 .
$$

Table 4 shows the scaled values. In this representation each column should contain the same heat flux value. As mentioned above all values are to be compared to the reference value measured using the $50 \mathrm{~mm}$,

Table 4: Results of the different methods scaled to $102 \mathrm{~mm}$ (4") hemispherical probe.

\begin{tabular}{lll}
\hline Probe & IRS-Ames-1 in W/cm & IRS-Ames-2 in W/cm \\
\hline \hline Water-cooled calorimeter $50 \mathrm{~mm}$, hemispherical & 74.4 & 236.8 \\
Water-cooled calorimeter $50 \mathrm{~mm}$, flat faced probe head & - & \\
Slug calorimeter $102 \mathrm{~mm}$ hemispherical & 79 & 184 \\
Slug calorimeter $50 \mathrm{~mm}$ flat faced & 84 & 180 \\
NASA Nullpoint & - & - \\
IRS Nullpoint $20 \mathrm{~mm}$ hemispherical & 30.9 & 229.9 \\
\hline
\end{tabular}

hemispherical water-cooled calorimeter from IRS, i.e. the first line in Tab. 4. The Ames slug calorimeter agree well at the low condition, but read about $20 \%$ lower at the high condition. One possible reason for the difference for the $4 "(102 \mathrm{~mm})$ hemispherical shape could be the rather large probe compared to the overall plasma flow diameter. This conclusion is only based on the visual impression of the sample on the center axis as seen in Fig. 5.

The IRS nullpoint agrees well for the high condition, but results in too low heat flux values at the low condition. Since this was the first testing at IRS of this design, the speed of the moving table was chose very high. This resulted in a rather moderate heating and thus only a small temperature rise. Together with the electromagnetic noise, the data was difficult to interpret.

Figure 12 shows the measured heat fluxes versus total pressure in both facilities. The IRS-Ames- 2 condition corresponds to the Ames-IRS-1 condition and was the condition desired to be the same. Open symbols denote data measured at Ames, the solid symbols correspond to the measurements at IRS. Both nullpoints, i.e. the $20 \mathrm{~mm}$ hemispherical probe and the $9.2 \mathrm{~mm}$ sphere-cone, were analyzed using the NISI approach. All data is scaled to the 4" $(102 \mathrm{~mm})$ hemispherical probe. For all conditions, the measured heat fluxes agree fairly well, but all nullpoint data available so far reads too low. The reason for this could be that sweeping speeds were chosen too high resulting in too low temperature data to be analyzed with an inverse method. However, this phenomenon should be further investigated. At the comparison condition (IRS-Ames-2 = Ames-IRS-1) and excluding the Ames nullpoint measurement, the heat flux data is in good agreement and differ by $8 \%$. At the low condition at IRS, the nullpoint data is by far too low, because the sweeping speed was again chosen too fast.

As a preliminary conclusion of the comparison within this project, the results indicate that the measurement methods are applicable to both facilities and the comparison condition of the facility is in good agreement.

\section{Summary}

This paper presents the first results of the second part of comparison measurements at Ames and IRS using various heat flux gages. The comparison of the sensors in the IRS facility shows good agreement, except for the hemispherical probe with the larger diameter. The photos from the experiment indicate that the large radius might be the reason, because the flow diameter at IRS is possibly not large enough. The NISI calibrated $20 \mathrm{~mm}$ hemispherical nullpoint data agrees well for the high condition, but does not measure useful data for the low condition. It was found that a slower traverse speed needs to be adjusted in order to get sufficient temperature rise for a reasonable data evaluation.

A comparison of the two flow conditions intended to be the same at the two facilities, i.e. IHF and PWK4, shows that measurements using hemispherical and flat faced probes with $50 \mathrm{~mm}$ diameter result in heat flux 


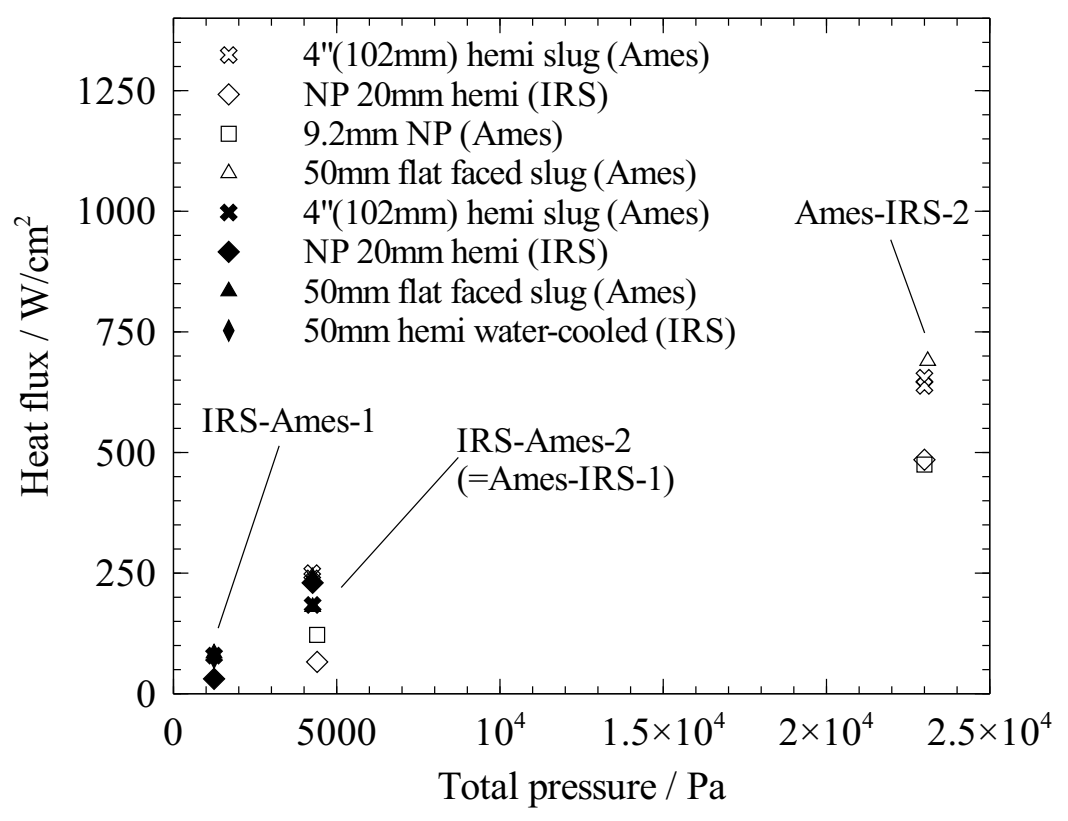

Fig. 12: Comparison of the measured data.

values that agree with the values measured at ARC.

The comparison is not yet finalized: The Ames nullpoint measurements and the $50 \mathrm{~mm}$ flat faced watercooled calorimeter data is still to be conducted. Furthermore, there are some more sensor designs planned to be tested.

As a preliminary conclusion based on the available data it is seen that clearly that this comparison is very useful for improving the understanding of heat flux measurements on copper surfaces. The difference in facility operation allows to interpret issues to be considered in the future, such as geometrical effects, surface oxidation state and flow contamination issues.

\section{Acknowledgment}

The authors would like to thank the facility crew and workshops at Ames and at IRS for their support in making this cooperation a success. The work of S. Loehle was partly supported by the German Research Foundation through grant No. 1772/1-1 which is gratefully acknowledged. A. Nawaz' funding through contract NNA16BD26C is gratefully acknowledged.

\section{References}

${ }^{1}$ Nawaz, A., Loehle, S., Herdrich, G., and Martinez, E. R., "Comparison of Calorimetric Sensors - Nasa Ames and IRS," 44th AIAA Thermophysics Conference, AIAA, 2013.

${ }^{2}$ Löhle, S., Battaglia, J.-L., Jullien, P., van Ootegem, B., Couzi, J., and Lasserre, J.-P., "Improvement of High Heat Flux Measurements using a null-point Calorimeter," Journal of Spacecrafts and Rockets, Vol. 45, No. 1, 2007, pp. 76-81.

${ }^{3}$ Frankel, J., Keyhani, M., and Elkins, B., "Surface heat flux prediction through physics-based calibration: part 1- theory," 50th AIAA Aerospace Sciences Meeting including the New Horizons Forum and Aerospace Exposition, 2012.

4 "Standard Test Method for Measuring Extreme Heat-Transfer Rates from High-Energy Environments Using a Transient, Null-Point Calorimeter (E 598-96)," Tech. rep., ASTM, 2002.

${ }^{5}$ Loehle, S., Fasoulas, S., Herdrich, G., Hermann, T., Massuti-Ballester, B., Meindl, A., Pagan, A. S., and Zander, F., "The Plasma Wind Tunnels at the Institute of Space Systems: Current Status and Challenges," 46th Aerodynamic Measurement Technology and Ground Testing Conference, AIAA, 2016.

${ }^{6}$ Auweter-Kurtz, M., Kurtz, H., and Laure, S., "Plasma Generators for Re-entry Simulation," Journal of Propulsion and Power, Vol. 12, No. 6, November-Dezember 1996, pp. 1053-1061. 
${ }^{7}$ Löhle, S., Untersuchung von Wiedereintrittsplasmen mit Hilfe laserinduzierter Fluoreszenzmessungen, Dissertation, Universität Stuttgart, Institut für Raumfahrsysteme, 2006.

${ }^{8}$ Lein, S., Entwicklung eines auf Emissionsspektroskopie basierenden Sensorsystems zum Einsatz auf Wiedereintrittsplattformen, Ph.D. thesis, Universität Stuttgart, 2012, to be published.

${ }^{9}$ Loehle, S., Steinbeck, A., and Fasoulas, S., "Local Mass-Specific Enthalpy Measurements with a New Mass Injection Probe," Jornal of Thermophysics and Heat Transfer, 2015, in press.

${ }^{10}$ Anderson, J. D., Hypersonic and High-Temperature Gas Dynamics, 2nd Edition, AIAA Education Series, 2nd ed., 2006.

${ }^{11}$ Löhle, S. and Lein, S., "Simultaneous Translational Temperature Measurements of Different Atomic Species in Plasma Flows Using Scanning Fabry-Perot Interferometry," Review of Scientific Instruments, Vol. 83, No. 053111, 2012.

${ }^{12}$ Terrazas-Salinas, I., Carballo, J. E., Driver, D. M., and Balboni, J. A., "Comparison of Heat Transfer Measurement Devices in Arc Jet Flows with Shear," 10th Thermophysics Conference, AIAA, 2010.

${ }^{13}$ Nawaz, A. and Santos, J., "Assessing Calorimeter Evaluation Methods in Convective and Radiative Heat Flux Environment," 10th AIAA/ASME Thermophysics Conference, AIAA, 2010.

14 "Standard Test Method for Measuring Heat Transfer Rate Using a Thermal Capacitance (slug) Calorimeter," ASTM Standard ASTM E 457-08, American Society for Testing and Materials, 2008.

${ }^{15}$ Laux, T., Herdrich, G., and Auweter-Kurtz, M., "Mechanische Sonden für Materialtests und Plasmadiagnostik am IRS," DGLR Jahrestagung 2001, No. DGLR-JT2001-167, DGLR, 2001.

${ }^{16}$ Fasoulas, S., Stöckle, T., and Auweter-Kurtz, M., "Measurement of Specific Enthalpy in Plasma Wind Tunnels Using a Mass Injection Probe," 32nd AIAA Thermophysics Conference, No. AIAA 1997-2496, AIAA, Atlanta, GA, 1997.

${ }^{17}$ Löhle, S., Auweter-Kurtz, M., and Eberhart, M., "Local Enthalpy Measurments in a Supersonic Arcjet Facility," Journal of Thermophysics and Heat Transfer, Vol. 21, No. 4, 2007, pp. 790-795.

${ }^{18}$ Nawaz, A., Driver, D., Terrazas-Salinas, I., and Sepka, S., "Surface Catalysis and Oxidation on Stagnation Point Heat Flux Measurements in High Enthalpy Arc Jets," 44th AIAA Thermophysics Conference, AIAA, 2013.

${ }^{19}$ Stöckle, T., Untersuchung der Oberflächenkatalyzität metallischer und keramischer Werkstoffe in Hochenthalpieströmungen, Dissertation, Universität Stuttgart, Institut für Raumfahrsysteme, 2000.

${ }^{20}$ Laux, T., Feigl, M., Auweter-Kurtz, M., and Stöckle, T., "Estimation of the Surface Catalycity of PVD Coatings by Simultaneous Heat Flux and LIF Measurements in High Enthalpy Air Flows," 34th Thermophysics Conference, No. AIAA2000-2364, AIAA, 2000.

${ }^{21}$ Löhle, S. and Frankel, J., "Physical Insight into NISI Parameters," 50th Aerospace Science Meeting and Exhibit, AIAA, 2012.

${ }^{22}$ Cerisier, M., "Caractérisation Optique du Cuivre ARA," Technical Report DO 469, CEA, Le Barp, France, 2006.

${ }^{23}$ Kennedy, W. S., Rindal, R. A., and Powars, C. A., "Heat Flux Measurement Using Swept Null Point Calorimetry," Journal of Spacecrafts and Rockets, Vol. 9, No. 4, 1972, pp. 668-675.

${ }^{24}$ Gardarein, J.-L., Battaglia, J.-L., and Löhle, S., "Heat flux sensor calibration using noninteger system identification: Theory, experiment, and error analysis," Review of Scientific Instruments, Vol. 80, No. 025103, 2009.

${ }^{25}$ Zoby, E. V. and Sullivan, E. M., "Effects Corner Radius on Stagnation Point Velocity Gradients on Blunt Axisymmtric Bodies," Technical Report NASA TM X-1067, NASA Langley Research Center, 1966.

26 "Standard Test Method for Calculation of Stagnation Enthalpy from Heat Transfer Theory and Experimental Measurements of Stagnation-Point Heat Transfer and Pressure (E 637-05)," Tech. rep., ASTM, 2005. 